\title{
Do as I Say or Do as I Do? How Social Relationships Shape the Impact of Descriptive and Injunctive Norms of Voting
}

\author{
Edward Fieldhouse ${ }^{1 \star}$ (i) and David Cutts ${ }^{2}(0)$ \\ ${ }^{1}$ University of Manchester, School of Social Sciences, UK and ${ }^{2}$ University of Birmingham, Birmingham, UK \\ ${ }^{*}$ Corresponding author. E-mail: ed.fieldhouse@manchester.ac.uk
}

(Received 16 April 2019; revised 27 November 2019; accepted 8 January 2020; first published online 17 June 2020)

\begin{abstract}
Social norms play an important role in our understanding of why people vote, yet very little is known about the relative importance of descriptive and injunctive norms for voter turnout or how normative influence is affected by the political and social relationship between citizens. Using political discussion network data from the British Election Study, this article examines the joint effect of descriptive and injunctive norms on turnout. It demonstrates that citizens follow the example of those closest to them (descriptive norms), especially their partner, but they also respond to social approval of voting from political discussants regardless of the nature of their relationship.
\end{abstract}

Keywords: injunctive norms; descriptive norms; turnout; civic duty; political discussion; networks; voting

There is widespread agreement that social norms play an important role in explaining why people vote (Blais 2000). Without reference to norms, political scientists have struggled to explain why people should vote at all (Riker and Ordeshook 1968). However, the literature on voter turnout has yet to properly establish the relative extent to which descriptive and injunctive norms matter, both separately and in combination, or whether this is conditional on the nature of the relationship between political discussants. Most prior research on voting norms has focused on the role of civic duty, which can be thought of as a personal normative belief rather than a social norm (Bicchieri 2017). Political science studies have tended to focus on civic duty rather than relational measures of norms, largely due to the greater availability of individual-level survey data compared to social network data. In previous comparisons of descriptive and injunctive norms of voting, the role of descriptive norms has generally been given precedent (for example Glynn, Huge and Lunney 2009).

In this article, we use political discussion network data to examine the role of injunctive and descriptive norms on voter turnout. We make three important contributions to the study of voter turnout. First, using theoretical insights from social psychology (Bicchieri 2005; Bicchieri 2017), we explicitly separate the roles of empirical and normative expectations and personal normative beliefs to make a theoretical distinction that should be incorporated into future research on turnout. Secondly, we introduce new and unique empirical evidence regarding the relative importance of these concepts. Contrary to prevalent evidence and assumptions, we show that - even when you allow for the role of civic duty and descriptive norms - injunctive norms, which have frequently been dismissed as secondary to descriptive norms, play an important role in voter turnout. Thirdly, by examining the joint effect of injunctive and descriptive norms on turnout, we believe our research is the first to show that citizens not only follow the example of those closest to them, but they also respond to social approval of voting from political discussants regardless of the nature of their relationship. 
More generally, we suggest that the theoretical and empirical lessons of this research can be extended beyond the sub-field of voter turnout to political behaviour more generally.

\section{Norms and turnout}

One of the greatest puzzles of political behaviour has been why should citizens vote when, in most elections, they will have almost no chance of determining the outcome (Riker and Ordeshook 1968). Perhaps the most influential and persuasive solution to this paradox has been the introduction of a consumption element to voting that does not depend on the outcome, the most frequently cited of which is the notion of duty (Fiorina 1976). However, although research consistently shows that civic duty is correlated with voter turnout (Blais 2000), this may be little more than tautology. The inclusion of civic duty simply shifts the puzzle from why people vote to why people believe it is their duty to vote (Barry 1970). The answer to this latter puzzle lies in social norms (Coleman 1990).

Much of the literature on social norms of voting has focused on what social psychologists refer to as personal normative beliefs (Bicchieri 2017), especially civic duty. For example, according to Blais (2000), what matters is not so much the threat of disapproval but rather the personal belief that voting is a moral obligation. Such normative beliefs may reflect internalized norms, in this case the belief that voting is a citizen's civic duty. More generally, they represent how a person believes they ought to behave, which may reflect moral or prudential motivations as well as social ones. In other words, normative beliefs do not depend on what others do.

In order to understand the importance of norms in voter turnout, it is necessary to differentiate between these normative beliefs and social norms. Bicchieri $(2005,11)$ provides a definition of social norms that makes this distinction.

A social norm is a rule of behaviour that individuals prefer to conform to on condition that they believe that (a) most people in their reference network conform to it (empirical expectation) and (b) most people in their reference network believe they ought to conform to it (normative expectation).

A descriptive norm exists when there is a preference to conform to how others behave (that is, there is an empirical expectation). In the case of voting, this would mean a citizen believes that other people in her reference group vote. Descriptive norms provide a cognitive shortcut when one is choosing how to behave in a given situation (Cialdini, Kallgren and Reno 1991) and may involve both co-ordination (for example, driving on the correct side of the road) and imitation (for example, copying successful behaviours) (Bicchieri 2017). A descriptive norm means that behaviour is conditional only on empirical expectations. That is, a person prefers to vote if people in their relevant reference network vote. In contrast, an injunctive norm exists if a behaviour is conditional on normative expectations. In other words, it relies on a perception of how others believe one should behave, and involves social approval or disapproval. In the case of an injunctive norm of voting, this means that other people in one's social network think they ought to vote, and this is reflected in social approval of voting or disproval of abstention. ${ }^{1}$ It is quite possible for a descriptive norm to exist without an injunctive norm, although they are likely to exist simultaneously. ${ }^{2}$

\footnotetext{
${ }^{1}$ In some contexts, the reverse - an injunctive norm of not voting - could exist in which discussants disapprove of voting and approve of abstention (Partheymüller and Schmitt-Beck 2012).

${ }^{2}$ For example, George is aware that most of his friends vote, and as a result he believes that this is a good (or normal) thing to do. George also likes to fit in with his friends and be like them by voting for the Labour Party. The descriptive norm is that most of his friends vote, so he will too. If he thinks they will not bother, he would most likely make the same decision (i.e., George's turnout is conditional on empirical expectations). However, most of his friends have never expressed any opinion that George ought to vote. We would therefore say that there is a descriptive norm of voting but not an injunctive one. Now imagine that some of George's friends frequently tell him that he would be not doing his duty if he did not vote: he would be letting down the Labour Party and they would be disappointed with him. He feels pressured by this. We might now say there is also an injunctive norm of voting.
} 
The important distinction between normative beliefs and social norms - both descriptive and normative - is that social norms are conditional on the behaviour of others (Bicchieri 2017; Rolfe 2012). In contrast, a personal normative belief, such as civic duty, is not conditional on social expectations: those who strongly believe that voting is a duty would prefer to vote regardless of their expectations of others (Bicchieri 2017). To understand and assess the impact of norms on voting behavior, we need to measure three different concepts.

1. Personal normative belief: I think one should vote.

2. Empirical expectation: most people in my reference network vote.

3. Normative expectation: I believe most people in my reference network think one should vote.

While there is a widespread assumption in the turnout literature that descriptive norms matter more than injunctive norms (Rolfe 2012), this is largely inferred from research into other behaviours, mainly unrelated to political science (Cialdini, Kallgren and Reno 1991). Very little research on turnout has actually made this distinction. Moreover, although there is much research supporting the importance of social pressure (Green and Gerber 2010), evidence of the impact of descriptive norms of voting is rather limited. In field experiments that manipulate the descriptive norm of voting, the message that most people vote tends to increase people's willingness to vote themselves (Gerber and Rogers 2009). In the small number of cases in which researchers have examined the combined effects of injunctive and descriptive norms of voting, the results are mixed. Some studies have found that descriptive norms of voting are more important than injunctive norms (Blais 2000; Glynn, Huge and Lunney 2009). One recent study found that 'most people are not subjected to strong injunctive pressure' and that 'descriptive norms seem to be even more important than injunctive norms' (Blais, Galais and Coulombe 2018, 10-11). By contrast, Panagopoulos, Larimer and Condon (2014) found evidence of injunctive norms but not descriptive norms, and no evidence of an interaction between the two. Others have found a moderating effect at the dyadic level: that the influence of injunctive norms is conditional on the presence of consistent descriptive norms (Bicchieri and Xiao 2009). In other words, an individual exerts more social pressure to vote if he or she votes themselves.

The intimacy of the relationship between discussants is also likely to be relevant to the influence of social norms of voting, because closer discussants - especially family members - are more likely to observe whether or not the subject votes, and therefore to apply sanctions (show disapproval) in the event of non-voting (Abrams et al. 2011; Coleman 1990). It is therefore important to allow for variation in the impact of social norms across different types of social relationships. We therefore propose the following hypotheses.

Hypothesis 1: Respondents with (more) discussants who vote (empirical expectations) will be more likely to vote themselves.

Нуротнеsis 2: Respondents with (more) discussants who care whether the respondent votes (normative expectations) will be more likely to vote themselves.

HyPOTHEsIs 3: The impact of normative and empirical expectations varies by social relationship.

Hypothesis 4: The impact of normative expectations is moderated by empirical expectations.

\section{Data and Methods}

We draw on data from Wave 2 of the British Election Study internet panel (Fieldhouse et al. 2017), fielded in May-June 2014, which included a specially designed module on political discussion designed to test social influences on turnout. The data set contains 30,895 individual respondents 
including 25,387 who named at least one political discussant, which formed the basis of a one-with-many dyadic design (Kenny et al. 2006). In total there were 56,282 dyads. Discussants were identified via a name generator approach: respondents were directed to think of three people with whom they talk about politics (following a question about the frequency of political discussion). ${ }^{3}$ Our key concepts are measured at two levels of analysis - the network (one for each respondent) and the dyad (one for each discussant). To measure normative expectations or injunctive norms at the dyadic level, respondents were asked the question 'Do you think this person cares whether or not you voted in the European Elections?' of each discussant. Responses to this question were aggregated across all respondents in the network. Empirical expectations or descriptive norms were measured at the dyadic level using the question: 'As far as you know, did each of these people vote in the recent European Elections?' At the network level, responses were again aggregated across all discussants. Personal normative beliefs were measured using a standard indicator of civic duty, which captures agreement with the statement 'It is every citizen's duty to vote in an election'.

We cannot assume that empirical and normative expectations are independent of each other. Each of our survey instruments measures respondents' perceptions; it seems plausible that respondents might base their assessments of social approval on knowledge of the behaviour of their discussants (which is more easily observable). Our data confirm that respondents are much more likely to perceive injunctive norms if they believe their discussant voted. Respondents largely believe that their discussants would expect them to 'practice what they preach': when considering discussants who they believe voted, respondents thought that 69 per cent of those discussants cared whether the respondent voted. This compares to only 20 per cent of discussants who did not vote. When assessing the impact of normative expectations, it is therefore important to control for empirical expectations and their interactive effect, since perceived approval depends on whether the discussant is a voter.

To test the extent to which the impact of injunctive and descriptive norms depends on the relationship between discussants, respondents were asked about their relationship with each discussant. The most commonly identified discussants were spouses, followed by other family and then friends; neighbours and co-workers made up the smallest group. While we are mainly interested in the differential impact of social norms rooted in different social relationships, it is important to note that exposure to those norms may also depend on the nature of the relationship. Our data confirm a correlation between relationship type and injunctive norms: spouses are the most likely to be thought to approve of voting (62 per cent), followed by other family members (50 per cent) and friends ( 44 per cent). Neighbours and co-workers were the least likely to be reported to care (29 per cent).

\section{Modelling Strategy}

There are two key steps in the modelling strategy. First, we model whether or not the respondents voted according to the characteristics of their network as well as their own characteristics (Hypotheses 1 and 2). In the second stage, we focus on the dyadic relationship between discussants and respondents. Although this requires removing the dyads from the context of the network, by focusing on interpersonal influence, we are able to explore how the impact of normative expectations varies according to the relationship between the respondent and the discussant (Hypotheses 3 and 4).

We test Hypotheses 1-2 using standard logistic regression models at the respondent or network level. The key explanatory variables are respondent-level empirical and normative expectations as described above. Because different respondents named different numbers of discussants, we stratify the models by the number of discussants in the network to avoid conflating the

\footnotetext{
${ }^{3}$ The question is worded as follows: 'Can you think of anyone you sometimes talk to about politics? These people might or might not be relatives. ${ }^{\star}$ Provide up to three names starting from the top box. For example, if you only to talk to one person please fill in the top box, if you talk to two people please fill in the top two boxes, if you do not talk to anybody please skip the

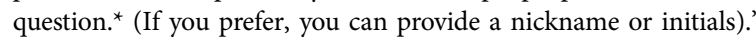


number of discussants who vote or care about voting with the size of the network. We focus mainly on three-discussant networks, as they contain the most information, but it is important to compare with smaller networks in case three-person networks are unusual in any way. Overall, 70 per cent of networks contain three discussants, 18 per cent two, and 12 per cent only one discussant. These models include a number of controls at the respondent level that are consistent with individual-level predictors of voter turnout (Smets and Van Ham 2013). This is important because numerous respondent characteristics may also influence discussants' selection and perceptions of social norms. Crucially, we include civic duty, which allows us to control for the possibility that perceiving a social norm in others may be related to personal normative beliefs. This variable is measured from the previous wave of the panel (Wave 1) to minimize the possibility that our measure of normative beliefs is a reflection of perceived injunctive norms. Additionally, we control for whether any of the discussants asked the respondent to vote. ${ }^{4}$ This enables us to separate the impact of interpersonal mobilization (Rosenstone and Hansen 1993) or a companion effect (Fieldhouse and Cutts 2012) from the co-ordination, informational or normative effects of empirical expectations. We also control for the strength of party identification (also lagged), political attention (lagged), political efficacy (lagged), party mobilization (measured as campaign contact), age, gender, education, marital status and the number of days on which the respondent typically discusses politics. The latter is important because the frequency of political discussion is closely related to the selection of discussants (for example, how likely they are to care) and the number of discussants the respondent selects. ${ }^{5}$

In the second stage, we again use a logistic regression model, but this time stratified by relationship type such that each case represents a single dyad. This allows us to examine the extent to which the impact of empirical and normative expectations varies by the nature of the relationship between the respondent and discussant, and whether or not the impact of normative expectations is conditional on empirical expectations. Empirical and normative expectations are measured at the dyadic level as described above. In other words, do citizens consider whether their discussants expect them to 'do as they say' even if they do not do so themselves? To avoid using the same respondent more than once in each model, we select the first instance of each relationship type named by each respondent. For example, in the friends model we take the first named friend of each respondent. The outcome variable is again turnout, and the key explanatory variables are dyadic normative and empirical expectations.

In these models we include a product interaction between normative and empirical expectations to allow us to test for the presence of an interactive as well as additive effect. It is well known that assessing interactions in logistic models is complicated by the effect of compression resulting from the bounded nature of the outcome (Ai and Norton 2003). In keeping with our theoretical expectations, we therefore include the product interaction terms in all the models regardless of conventional statistical significance because not only are such significance tests unreliable, but because including the product interaction improves the model estimation even in the absence of interaction in the data-generating process (Berry, DeMeritt and Esarey 2010; Berry, DeMeritt and Esarey 2016; Rainey 2016). We carry out and report various methods of estimating and visualizing the direction and importance of the interactions.

We control for the same individual-level variables as in the network turnout model and the dyadic variable, capturing whether or not the discussant invited the respondent to go to vote together. This variable helps us differentiate between the effect of normative pressure and interpersonal mobilization. However, arguably, this might partly reflect a norm of voting: if you ask

\footnotetext{
${ }^{4}$ 'Thinking back to the day of the elections on May 22nd, did any of these people ask you to go to vote together?' ${ }^{\star}$ Please tick all that apply.*

${ }^{5}$ In our data the average number of days discussing politics was 2.3 for respondents naming one discussant, 3.2 for two discussants and 4.4 for three discussants. Our data also show that perceived discussant approval increases with the frequency of discussion: those who discuss politics on a daily basis are more than three times as likely to perceive approval as those discussing politics less than once per week.
} 
Table 1. Logistic model of European Parliament election turnout by empirical and normative expectations

\begin{tabular}{|c|c|c|c|c|c|c|}
\hline \multirow[b]{2}{*}{ Variables } & \multicolumn{2}{|c|}{ One discussant } & \multicolumn{2}{|c|}{ Two discussants } & \multicolumn{2}{|c|}{ Three discussants } \\
\hline & $\beta$ & s.e. & $\beta$ & s.e. & $\beta$ & s.e. \\
\hline Constant & $-3.76^{\star}$ & 0.29 & $-3.43^{*}$ & 0.37 & $-3.01^{*}$ & 0.25 \\
\hline \multicolumn{7}{|l|}{ Network variables } \\
\hline Empirical expectations & $1.80^{\star}$ & 0.09 & $1.15^{\star}$ & 0.07 & $0.74^{\star}$ & 0.03 \\
\hline Normative expectations & $0.86^{\star}$ & 0.09 & $0.47^{\star}$ & 0.06 & $0.42^{\star}$ & 0.03 \\
\hline Asked to Vote & $0.56^{\star}$ & 0.12 & $1.03^{\star}$ & 0.14 & $1.04^{\star}$ & 0.10 \\
\hline \multicolumn{7}{|l|}{ Respondent variables } \\
\hline Overall party contact & $0.40^{\star}$ & 0.09 & $0.73^{\star}$ & 0.10 & $0.53^{\star}$ & 0.07 \\
\hline Discuss politics & $0.06^{\star}$ & 0.02 & 0.01 & 0.03 & $0.04^{\star}$ & 0.02 \\
\hline Political attention (lagged) & $0.06^{\star}$ & 0.02 & $0.07^{\star}$ & 0.03 & $0.09^{*}$ & 0.02 \\
\hline Efficacy don’t understand (lagged) & $-0.09^{\star}$ & 0.04 & $-0.10^{\star}$ & 0.05 & $-0.12^{\star}$ & 0.03 \\
\hline Party ID \& strength (Combined) (lagged) & $0.23^{*}$ & 0.05 & $0.17^{*}$ & 0.06 & $0.15^{*}$ & 0.04 \\
\hline Civic duty (personal norms) (lagged) & $0.47^{\star}$ & 0.04 & $0.42^{\star}$ & 0.05 & $0.39^{*}$ & 0.03 \\
\hline Female & $-0.43^{\star}$ & 0.08 & $-0.42^{\star}$ & 0.09 & $-0.48^{\star}$ & 0.07 \\
\hline \multicolumn{7}{|l|}{ Age categories: under 26} \\
\hline Age $26-35$ & $0.62^{*}$ & 0.19 & 0.25 & 0.23 & 0.22 & 0.14 \\
\hline Age $36-45$ & $0.89^{\star}$ & 0.19 & $0.61^{\star}$ & 0.22 & $0.60^{\star}$ & 0.14 \\
\hline Age $46-55$ & $1.04^{\star}$ & 0.19 & $0.89^{\star}$ & 0.22 & $0.78^{\star}$ & 0.13 \\
\hline Age $56-65$ & $1.28^{\star}$ & 0.18 & $0.90^{\star}$ & 0.21 & $0.92^{\star}$ & 0.13 \\
\hline Age 66 plus & $1.60^{\star}$ & 0.19 & $1.01^{\star}$ & 0.22 & $1.15^{\star}$ & 0.13 \\
\hline \multicolumn{7}{|l|}{ Education: all others } \\
\hline Degree or more & 0.10 & 0.08 & $0.27^{\star}$ & 0.09 & $0.20^{\star}$ & 0.07 \\
\hline \multicolumn{7}{|l|}{ Model fit } \\
\hline$\chi^{2}<0.05$ & \multicolumn{2}{|c|}{$2,177.06^{\star}$} & \multicolumn{2}{|c|}{$1,445.61^{*}$} & \multicolumn{2}{|c|}{$2,849.34^{\star}$} \\
\hline Log likelihood & \multicolumn{2}{|c|}{$-2,318.20$} & \multicolumn{2}{|c|}{$-1,698.86$} & \multicolumn{2}{|c|}{$-3,361.76$} \\
\hline McFadden $R^{2}$ & \multicolumn{2}{|c|}{0.32} & \multicolumn{2}{|c|}{0.30} & \multicolumn{2}{|c|}{0.30} \\
\hline $\mathrm{AIC}$ & \multicolumn{2}{|c|}{$4,670.40$} & \multicolumn{2}{|c|}{$3,431.73$} & \multicolumn{2}{|c|}{$6,757.53$} \\
\hline$N$ & \multicolumn{2}{|c|}{5,616} & \multicolumn{2}{|c|}{4,336} & \multicolumn{2}{|c|}{11,070} \\
\hline
\end{tabular}

Note: data are unweighted. *Significant $<0.05$

someone to vote, you are signalling not only that you will vote yourself but also that you believe the person you ask should also vote. Consequently, including this provides a tough test of the impact of social norms, although the possibility of endogeneity remains. This is discussed further below.

\section{Results}

Table 1 shows the results of the network turnout model and provides support for Hypotheses 1 and 2. Controlling for a wide range of network and individual characteristics, including civic duty, we find that both empirical expectations and normative expectations have an independent effect on the probability of voting in the European Parliament elections. This is true across all network sizes; the size of the effect is smaller in larger networks. This is most likely because where respondents have only one or two discussants, these are likely to be relatively more influential and are frequently spouses or other close family members. Moreover, for all network sizes, empirical expectations appear to be more important than normative expectations. To illustrate this more clearly, we can visualize the predicted probability of voting from the three-discussant model by both the number of discussants who voted and the number who approve (Figure 1). Holding empirical expectations constant, we find that for any given number of discussants who voted, there is an increase in turnout according to the level of normative expectations (how many discussants care about voting).

Figure 2 suggests that the impact of both empirical and normative expectations vary according to the level of the other, in keeping with compression interaction common in logistic regression models (Nagler 1991). To assess the relative importance of each, we plot the average marginal 
Figure 1. Probability of voting by number of discussants who vote and who care whether respondent votes in three person networks (when number of discussants $=3$ ). Error bars denote $95 \%$ confidence interval.

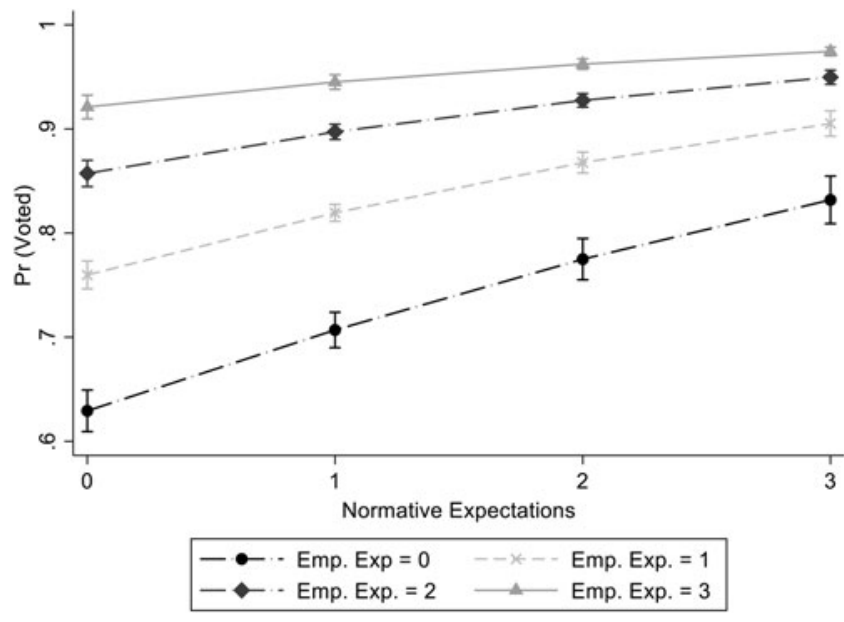

Figure 2. Comparison of Average marginal effect of Normative Expectations by Empirical Expectations; and Empirical Expectations by Normative Expectations (respondents with 3 discussants only). Error bars denote $95 \%$ confidence interval.

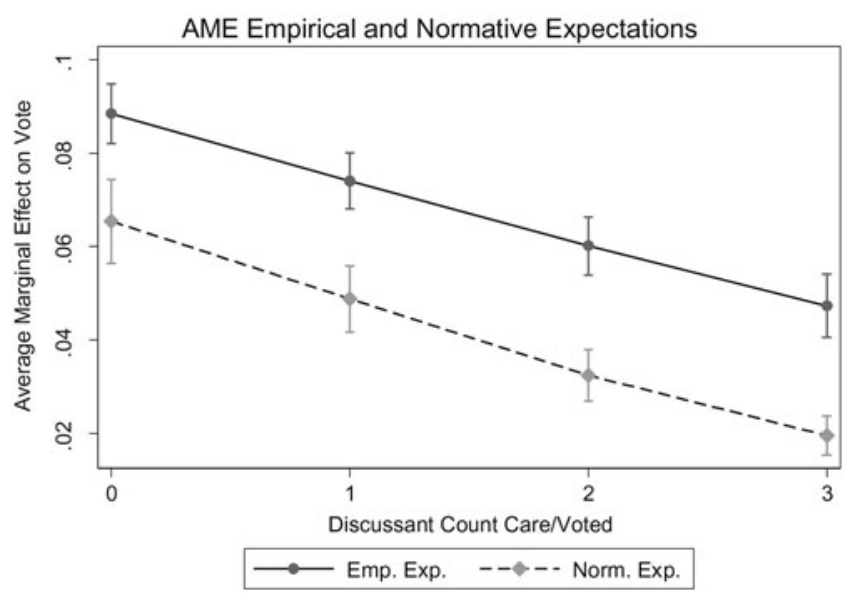

effect of both variables across the full range (0-3) of the other variable and superimpose these on the same chart (Figure 2). Thus in the normative expectations plot the $\mathrm{x}$-axis represents the count of discussants who voted and in the empirical expectations plot, the $\mathrm{x}$-axis represents the number of discussants who care whether the respondent votes. At all values of these variables, the average marginal effect of empirical expectations is larger than that of normative expectations. However, as Table 1 indicates, both variables have substantial effects on the probability of voting even after controlling for personal normative beliefs and a host of other correlates of individual turnout. For example, when the respondent has one discussant who cares whether s/he votes, each discussant who votes themselves increases turnout by approximately 7 per cent. Similarly, for a respondent who has one discussant who voted, each discussant who cares whether s/he votes increases turnout by around 6 per cent. The overall average marginal effect of empirical expectations for respondents who have three discussants is 7 per cent and for normative expectations it is 4 per cent.

As explained above, to test Hypothesis 3 (that relationship type moderates the impact of normative and empirical expectations) and Hypothesis 4 (that there is an interaction between empirical and normative expectations) we stratified our analyses so that we have a separate model for 
Table 2. Logistic model of dyad relationship turnout by normative and empirical expectations

\begin{tabular}{|c|c|c|c|c|c|c|c|c|}
\hline \multirow[b]{2}{*}{ Variables } & \multicolumn{2}{|c|}{ Spouse } & \multicolumn{2}{|c|}{ Family } & \multicolumn{2}{|c|}{ Friends } & \multicolumn{2}{|c|}{ Neigh/other } \\
\hline & $\beta$ & s.e. & $\beta$ & s.e. & $\beta$ & s.e. & $\beta$ & s.e. \\
\hline Constant & $-2.40^{*}$ & 0.26 & $-2.01^{*}$ & 0.21 & $-2.26^{\star}$ & 0.21 & $-1.64^{\star}$ & 0.26 \\
\hline \multicolumn{9}{|l|}{ Network variables } \\
\hline Empirical expectations & $2.58^{\star}$ & 0.09 & $0.93^{\star}$ & 0.08 & $0.82^{*}$ & 0.08 & $0.93^{*}$ & 0.10 \\
\hline Normative expectations & $0.67^{\star}$ & 0.09 & $1.07^{\star}$ & 0.10 & $0.64^{\star}$ & 0.10 & $0.55^{\star}$ & 0.15 \\
\hline Empirical Exp $\times$ normative Exp & $0.40^{\star}$ & 0.14 & -0.07 & 0.14 & 0.23 & 0.14 & -0.25 & 0.20 \\
\hline Asked to Vote & $0.62^{\star}$ & 0.10 & $0.57^{\star}$ & 0.16 & 0.01 & 0.22 & -0.39 & 0.23 \\
\hline \multicolumn{9}{|l|}{ Respondent variables } \\
\hline Overall party contact & $0.60^{\star}$ & 0.07 & $0.66^{\star}$ & 0.06 & $0.62^{*}$ & 0.06 & $0.49^{\star}$ & 0.08 \\
\hline Discuss politics & $0.11^{\star}$ & 0.02 & $0.13^{*}$ & 0.02 & $0.13^{*}$ & 0.02 & $0.13^{*}$ & 0.02 \\
\hline Political attention (lagged) & $0.08^{\star}$ & 0.02 & $0.07^{\star}$ & 0.02 & $0.12^{\star}$ & 0.02 & $0.06^{\star}$ & 0.02 \\
\hline Efficacy don't understand (lagged) & $-0.10^{\star}$ & 0.03 & $-0.11^{*}$ & 0.03 & $-0.08^{\star}$ & 0.03 & $-0.17^{\star}$ & 0.04 \\
\hline Party ID \& strength (combined) (lagged) & $0.19^{\star}$ & 0.04 & $0.21^{\star}$ & 0.04 & $0.18^{\star}$ & 0.04 & $0.32^{\star}$ & 0.04 \\
\hline Civic duty (personal norms) (lagged) & $0.74^{\star}$ & 0.08 & $0.90^{*}$ & 0.07 & $0.94^{\star}$ & 0.07 & $0.97^{\star}$ & 0.08 \\
\hline Female & $-0.43^{*}$ & 0.06 & $-0.24^{*}$ & 0.06 & $-0.22^{*}$ & 0.06 & $-0.26^{\star}$ & 0.07 \\
\hline \multicolumn{9}{|l|}{ Age categories: under 26} \\
\hline Age $26-35$ & 0.21 & 0.19 & 0.19 & 0.13 & 0.15 & 0.13 & 0.33 & 0.18 \\
\hline Age $36-45$ & 0.31 & 0.19 & $0.41^{\star}$ & 0.12 & $0.67^{\star}$ & 0.13 & $0.56^{\star}$ & 0.18 \\
\hline Age $46-55$ & $0.38^{\star}$ & 0.19 & $0.77^{\star}$ & 0.12 & $0.83^{*}$ & 0.13 & $0.88^{\star}$ & 0.17 \\
\hline Age 56-65 & $0.36^{\star}$ & 0.18 & $0.91^{\star}$ & 0.11 & $0.93^{*}$ & 0.12 & $1.01^{\star}$ & 0.17 \\
\hline Age 66 plus & $0.43^{*}$ & 0.19 & $1.18^{*}$ & 0.12 & $1.19^{*}$ & 0.12 & $1.45^{\star}$ & 0.19 \\
\hline \multicolumn{9}{|l|}{ Education: all others } \\
\hline Degree or more & $0.23^{*}$ & 0.07 & $0.26^{*}$ & 0.06 & $0.17^{\star}$ & 0.06 & 0.14 & 0.08 \\
\hline \multicolumn{9}{|l|}{ Model fit } \\
\hline$\chi^{2}<0.05$ & \multicolumn{2}{|c|}{$3,098.32^{\star}$} & \multicolumn{2}{|c|}{$1,607.26^{\star}$} & \multicolumn{2}{|c|}{$1,331.29^{\star}$} & \multicolumn{2}{|c|}{$944.82^{\star}$} \\
\hline Log likelihood & \multicolumn{2}{|c|}{$-3,531.44$} & \multicolumn{2}{|c|}{$-3,840.70$} & \multicolumn{2}{|c|}{$-3,745.24$} & \multicolumn{2}{|c|}{$-2,517.52$} \\
\hline McFadden $R^{2}$ & \multicolumn{2}{|c|}{0.44} & \multicolumn{2}{|c|}{0.22} & \multicolumn{2}{|c|}{0.20} & \multicolumn{2}{|c|}{0.20} \\
\hline AIC & \multicolumn{2}{|c|}{$7,098.89$} & \multicolumn{2}{|c|}{$7,717.41$} & \multicolumn{2}{|c|}{$7,526.48$} & \multicolumn{2}{|c|}{$5,071.05$} \\
\hline$N$ & \multicolumn{2}{|c|}{12,600} & \multicolumn{2}{|c|}{9,805} & \multicolumn{2}{|c|}{9,713} & \multicolumn{2}{|c|}{5,929} \\
\hline
\end{tabular}

Note: data are unweighted. * Significant $<0.05$

each type of relationship (see Table 2). We see that the control variables have a fairly consistent effect across models. It is important to note the impact of the Asked to Vote variable. Interpersonal influence might take the form of direct mobilization or companion effects (Fieldhouse and Cutts 2012) and not require any normative component. Simply being 'invited' to vote by a family member appears to be an important predictor of turnout, but the same is not true for non-family members. Voting together is very much a household phenomenon (Bhatti, Fieldhouse and Hansen 2018; it is therefore not surprising that an invitation to vote together is powerful only among family members. Nevertheless, even allowing for this, both injunctive and descriptive norms are important. Moreover, although it might be reasonable to assume that mobilization (especially by a spouse) might mediate the effect of both types of norms, it is worth noting that when we ran the same model without including the Asked to Vote variable, the parameter estimated for empirical and normative expectations barely changed. ${ }^{6}$ The only instance in which controlling for personal mobilization makes a non-negligible difference is in the case of spousal empirical expectations. That is, when we control for being asked to vote by a spouse, the effect of empirical expectations is slightly smaller. Given that spouses frequently vote together, it is perhaps surprising that adding this control does not make an even greater difference. In short, we find little evidence that injunctive or descriptive norms are being mediated by (or are attributable to) interpersonal mobilization.

\footnotetext{
${ }^{6}$ The estimates for empirical expectations in the same model without Asked to Vote were as follows (values from the model in Table 2 in parentheses): spouse 2.74 (2.58), other family $0.96(0.93)$, friends $0.82(0.82)$ and other $0.92(0.93)$. For normative expectations the estimates were: spouse 0.69 (0.67), other family 1.08 (1.07), friends $0.64(0.64)$ and other $0.55(0.55)$.
} 
Figure 3. Average marginal effects of dyadic normative and empirical expectations by relationship type. Error bars denote 95\% confidence interval.

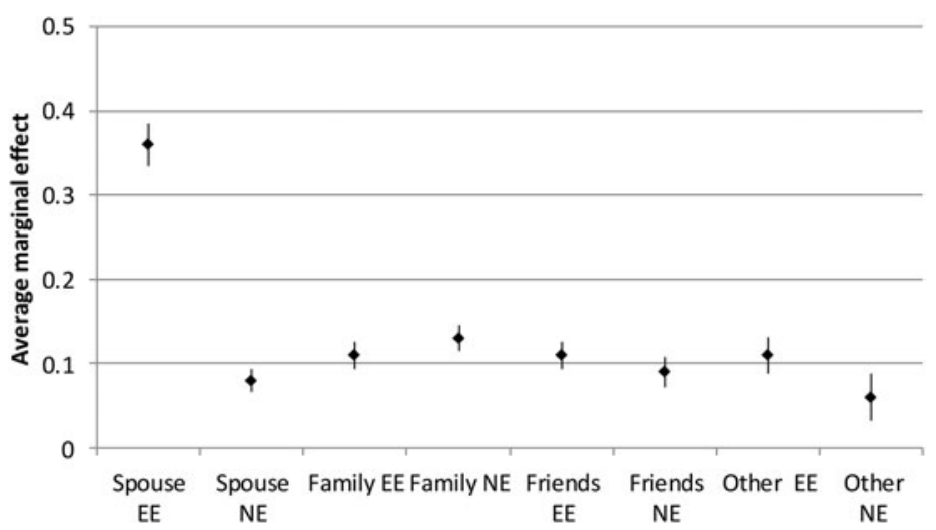

Turning to those parameter estimates for the norms variables, it is clear that empirical expectations - or descriptive norms - are especially important for spouses and somewhat less important for other types of relationship. Normative expectations have a more consistent effect across relationship types, although the effects are slightly weaker for neighbours and co-workers. Such expectations are actually stronger for family members other than spouses - most likely children or parents. Overall, the magnitude of the effect of normative expectations is on a par with empirical expectations except in the case of spouses.

The overall relative importance of empirical and normative expectations is illustrated in Figure 3, which shows the average marginal effects of each variable by relationship type. The plot highlights the special importance of empirical expectations for spouses, and confirms the importance of both empirical and normative expectations for all types of political discussants. A respondent who has a spouse who voted is, on average, approximately 36 percentage points more likely to vote than one with a spouse who does not. This is consistent with research showing a high level of correspondence in turnout within households, especially among spouses (Cutts and Fieldhouse 2009). Although we control for direct interpersonal mobilization (Asked to Vote), there may be a variety of reasons for this correspondence that are not normative. On average, having a spouse who cares whether you vote raises turnout by about 8 percentage points. For other relationship types, empirical and normative expectations have a much more similar impact. Indeed, outside of spousal relationships, social approval of voting is equally as important as descriptive norms.

\section{Assessing Interactive Effects}

It is widely recognized that the statistical significance and point estimates of interactions are problematic to interpret (Ai and Norton 2003; Berry, DeMeritt and Esarey 2010). In order to understand the interactive effects of two independent variables in a binary logit model, it is important to examine the marginal effects of each variable as the other varies. To assess the joint effect of empirical and normative expectations on turnout (Hypothesis 4) we therefore plot the predicted probabilities of voting by empirical and normative expectations for each relationship type (Figure 4). It is clear from the plot that there are notable slopes and gaps across all relationship types, demonstrating the impact of normative and empirical expectations, respectively. However, the evidence for an interactive relationship is mixed.

The predictive margin for spouses shown in Figure 4 appears to suggest an interactive relationship between normative and empirical expectations, but not in in a way that is consistent with the positive interaction shown in Table 2. Rather, the impact of normative expectations seems to be smaller in the presence of empirical expectations: the difference between having a spouse who cares about voting is roughly 6 percentage points if they voted themselves, compared with 15 

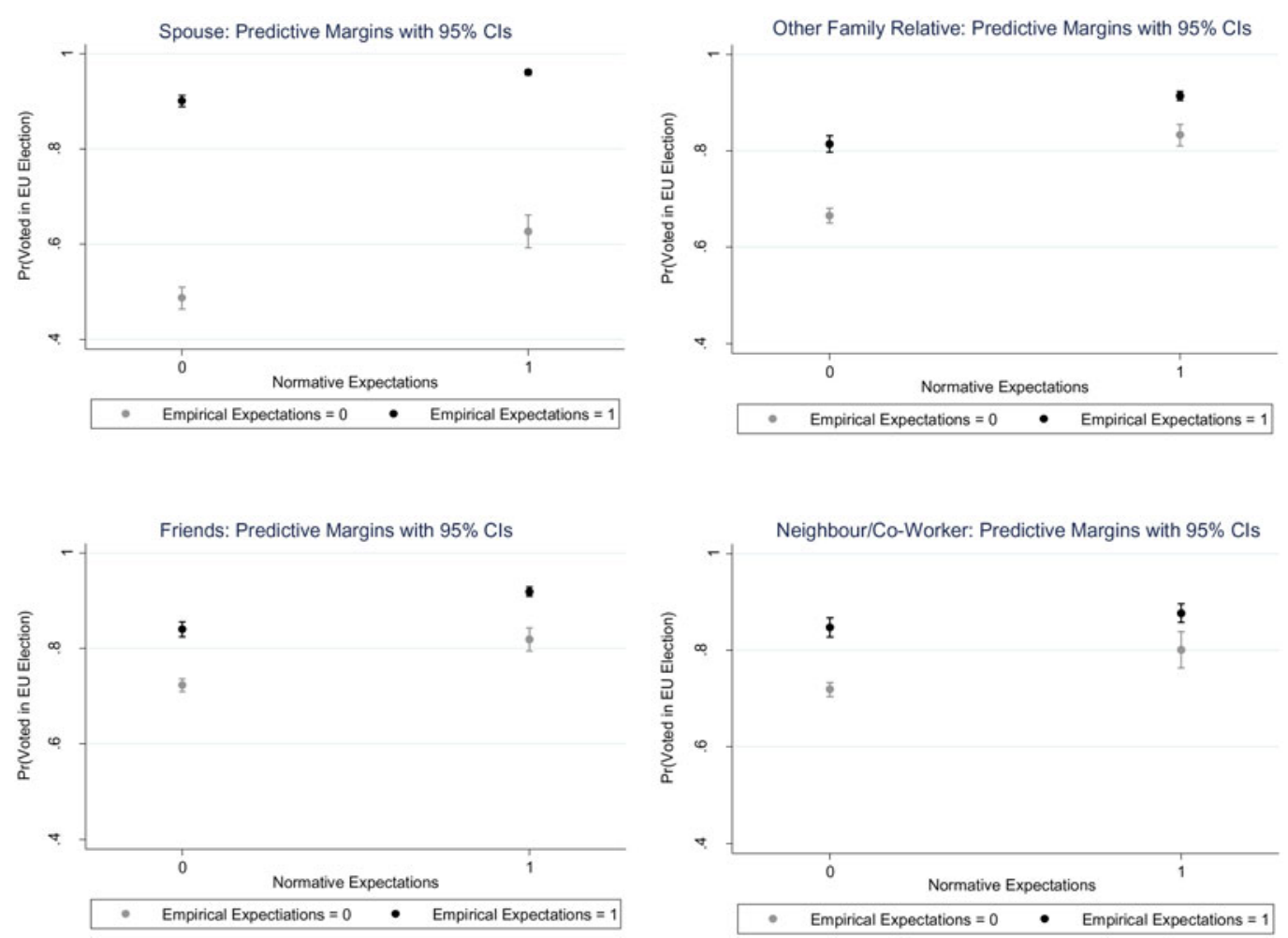

Figure 4. Predictive margins Normative and empirical expectations (dyadic models). Error bars denote $95 \%$ confidence interval.

percentage points if they did not. In other words, contrary to Hypothesis 4, if a spouse votes, whether or not they care about whether their partner votes seems to matter less.

This also appears to be to be true (to a lesser extent) for other family members, but not friends or neighbours/co-workers. However, taken together, the plots and interaction effects suggest that the primary driver in this interaction is compression. If a spouse votes (empirical expectations = 1) the chance of the respondent voting is already very high. If the probability of voting $\mathrm{P}(\mathrm{Y})$ is a function of an unbounded latent utility for voting $\left(\mathrm{Y}^{\star}\right)$ then we would expect that when a spouse votes the average latent utility for voting is much higher. Assuming (as is the case in our data) the mean probability of voting is greater than 0.5 , then depending on the distribution of $\mathrm{Y}^{\star}$, it is less likely that an increase in $\mathrm{Y}^{\star}$ due to social pressure will meet the utility threshold required for voting to be exceeded (Berry, DeMeritt and Esarey 2010; Nagler 1991). In other words, there is a lower chance that social pressure will matter if your partner votes, because it is more than likely that you would have voted anyway.

As noted above, in a model containing a product interaction we need to consider both that interaction (which in this case is positive) and the effect of compression (Berry, DeMeritt and Esarey 2016; Rainey 2016). The evidence shown in Appendix 1, including the second difference in marginal effects and the change in model fit, suggests that there is an interactive relationship in the case of spouses and other family, but not for other relationship types (see Appendix Table A1).

In sum, the preferred models (those with a product interaction) suggest that injunctive norms matter less if a spouse or family member votes themselves (compared to when the discussant does not vote) insofar as social pressure is less likely to be decisive in decisions about whether to vote. Indeed, spousal voting is very often a sufficient condition for voting (Fieldhouse and Cutts 2012). 


\section{Discussion}

This study is the first to use network data drawn from a sample of the general population to examine the relative importance of injunctive and descriptive norms for voter turnout, the extent to which their effects are interactive or additive, and how their influence varies across different social relationships. We show that descriptive and injunctive norms of voting are closely related, but allowing for this we find that both play an important role in voter turnout. While on the face of it our results are consistent with the orthodox view that descriptive norms are more important than injunctive norms, there are two reasons why this is not the conclusion that we draw.

First, while our research used the best available network data and our models controlled for a large array of potential confounding variables including civic duty, interpersonal mobilization, political interest and party identification, the processes of normative influence are, by definition, subject to endogeneity (that is, people influence each other). For example, respondents may take their own voting behaviour as evidence of what others are most likely do, or they may be more likely to select discussion partners with similar political tastes (Bello and Rolfe 2014). Moreover, just as discussants influence respondents, respondents also influence discussants. This is problematic for the dyadic measure of descriptive norms, since that simply measures whether the respondent believes the discussant voted. Therefore, when analysing the effect of this on the respondent's turnout, we capture the correspondence in turnout. Previous research has shown that such levels of correspondence are high (Cutts and Fieldhouse 2009) and have a large causal component (Bhatti, Fieldhouse and Hansen 2018), yet that correspondence may be the result of influence in either direction. While we explicitly controlled for interpersonal mobilization and companion effects, the effects of co-ordination and imitation may run from respondent to discussant or from discussant to respondent. It is therefore prudent to assume that the actual effect of descriptive norms is only half that of the estimated effect size for our Empirical Expectations variable. In contrast, while there are other potential sources of endogeneity - for example, if respondents infer that discussants approve of their voting because they themselves care about voting - there is no equivalent double counting of the effect of normative expectations: the survey question explicitly refers to social approval of the discussant and not the reverse.

Secondly, our findings clearly demonstrate that the relative importance of descriptive norms is limited to spouses. Given that couples are most likely to observe each other's voting behaviour and frequently make joint decisions about whether to vote (Cutts and Fieldhouse 2009; Fieldhouse and Cutts 2012; Glaser 1959), this is not altogether surprising. Across all other relationship types, injunctive norms have an impact on voter turnout that is equally as large as descriptive norms, and considerably larger if we assume, as argued above, that the effects of the descriptive norms are only half their estimated size. While we cannot eradicate all possible sources of endogeneity in the effect of both descriptive and injunctive norms on turnout, having set a tough test of their impact through our choice of control variables, we can be reasonably confident in making such a relative assessment.

Our findings regarding the interactive effect of injunctive and descriptive norms were nuanced. There is some evidence that empirical and normative expectations combined in a complex way, and that the effect of social pressure is smaller when a discussant voted. However, we noted that this is largely due the fact that, for spouses in particular, there was not much room for those with partners who voted to be influenced by social pressure as their likelihood of voting was already very high. If anything, this 'compression' was offset somewhat by an increased sensitivity to social pressure from spouses who voted.

These findings have important implications for the study of voter turnout and political behaviour more generally. We should not assume that the effects of normative influences on voter turnout can be measured simply by relying on the notion of civic duty. Internalized normative beliefs are important, but voter turnout is conditional on the norms, beliefs and actions of social referents, especially those who are socially most intimate. Nor should we assume that such normative 
influence is purely behavioural or descriptive. While in the case of married couples it is clear that whether or not a spouse votes themselves is crucial for voter turnout, for all other types of political discussants injunctive norms are equally important (or perhaps more so). It appears that political discussant partners are inclined to not only 'do as you do' but also 'do as you say'. Thus we conclude that even in the age of social media and the proliferation of political information, political discussion with social intimates still has a crucial influence over the social norms that underpin political participation.

Supplementary material. Data replication sets are available at: https://doi.org/10.7910/DVN/5VEL6S and online appendices are available at https://doi.org/10.1017/S0007123420000058.

Acknowledgements. This research was supported by Economic and Social Research Council grant number ES/K005294/1.

\section{References}

Abrams S, Iversen T and Soskice D (2011) Informal social networks and rational voting. British Journal of Political Science 41(2), 229-257.

Ai C and Norton EC (2003) Interaction terms in logit and probit models. Economics Letters 80, 123-129.

Barry BM (1970) Sociologists, Economists, and Democracy. London: Sollier-Macmillan.

Bello J and Rolfe M (2014) Is influence mightier than selection? Forging agreement in political discussion networks during a campaign. Social Networks 36, 134-146.

Berry WD, DeMeritt JHR and Esarey J (2010) Testing for interaction in binary logit and probit models: is a product term essential? American Journal of Political Science 54(1), 248-266.

Berry WD, DeMeritt JHR and Esarey J (2016) Bias and overconfidence in parametric models of interactive processes. American Journal of Political Science 60(2), 521-539.

Bhatti Y, Fieldhouse E and Hansen KM (2018) It's a group thing: how voters go to the polls together. Political Behavior.

Bicchieri C (2005) The Grammar of Society. Cambridge: Cambridge University Press.

Bicchieri C (2017) Norms in the Wild: How to Diagnose, Measure, and Change Social Norms. New York: Oxford University Press.

Bicchieri C and Xiao E (2009) Do the right thing: but only if others do so. Journal of Behavioral Decision Making 22(2), 191-208.

Blais A (2000) To Vote or not to Vote? The Merits and Limits of Rational Choice Theory. Pittsburgh, PA: University of Pittsburgh Press.

Blais A, Galais C and Coulombe M (2018) The effect of social pressure from family and friends on turnout. Journal of Social and Personal Relationships 36 (9), 2824-2841.

Cialdini R, Kallgren C and Reno R (1991) A focus theory of normative conduct: a theoretical refinement and reevaluation of the role of norms in human behavior. Advances in Experimental Social Psychology 24, 201-234.

Coleman JS (1990) Foundations of Social Theory. Cambridge, MA, London: Harvard University Press.

Cutts D and Fieldhouse E (2009) What small spatial scales are relevant as electoral contexts for individual voters? The importance of the household on turnout at the 2001 general election. American Journal of Political Science 53(3), 726-739.

Fieldhouse E et al. (2017) 'British Election Study, 2015: Internet Panel Survey, Waves 1-13 [computer file]'.

Fieldhouse E and Cutts D (2012) The companion effect: household and local context and the turnout of young people. The Journal of Politics 74(3), 856-869.

Fieldhouse E and Cutts D (2020) "Replication data for "Do as I say or do as I do? How social relationships shape the impact of descriptive and injunctive norms of voting”", https://doi.org/10.7910/DVN/5VEL6S, Harvard Dataverse, V1, UNF:6: QQEL86mizJ6KnNNZu4jE+g==[fileUNF].

Fiorina MP (1976) Voting decision - instrumental and expressive aspects. Journal of Politics 38(2), 390-413.

Gerber AS and Rogers T (2009) Descriptive social norms and motivation to vote: everybody's voting and so should you. The Journal of Politics 71(1), 178-191.

Glaser WA (1959) The family and voting turnout. Public Opinion Quarterly 23(4), 563-570.

Glynn CJ, Huge ME and Lunney CA (2009) The influence of perceived social norms on college students' intention to vote. Political Communication 26(1), 48-64.

Green DP and Gerber AS (2010) Introduction to social pressure and voting: new experimental evidence. Political Behavior 32(3), 331-336.

Kenny DA, Kashy DA and Cook WL(2006) Dyadic data analysis. New York, N.Y.: Guilford Press.

Nagler J (1991) The effect of registration laws and education on U.S. voter turnout. The American Political Science Review 85 (4), 1393-1405.

Panagopoulos C, Larimer CW and Condon M (2014) Social pressure, descriptive norms, and voter mobilization. Political Behavior 36(2), 451-469. 
Partheymüller J and Schmitt-Beck R (2012) A “social logic" of demobilization: the influence of political discussants on electoral participation at the 2009 German federal election. Journal of Elections, Public Opinion \& Parties 22(4), 457-478.

Rainey C (2016) Compression and conditional effects: a product term is essential when using logistic regression to test for interaction. Political Science Research and Methods 4(3), 621-639.

Riker WH and Ordeshook PC (1968) A theory of calculus of voting. American Political Science Review 62(1), 25-42.

Rolfe M (2012) Voter Turnout: A Social Theory of Political Participation, Political Economy of Institutions and Decisions. New York, Cambridge: Cambridge University Press.

Rosenstone SJ and Hansen JM (1993) Mobilization, Participation, and Democracy in America. New York: Macmillan.

Smets K and Van Ham C (2013) The embarrassment of riches? A meta-analysis of individual-level research on voter turnout. Electoral Studies 32(2), 344-359.

Cite this article: Fieldhouse E, Cutts D (2021). Do as I Say or Do as I Do? How Social Relationships Shape the Impact of Descriptive and Injunctive Norms of Voting. British Journal of Political Science 51, 1516-1528. https://doi.org/10.1017/ S0007123420000058 